\title{
Study on Voluntary Information Disclosure and Stock Price Synchronicity: Evidence from Chinese Listed Companies
}

\author{
Ben-Zhao Zhang ${ }^{1, a}$, Sheng-Jie Niu ${ }^{1, b,{ }^{*}}$ \\ ${ }^{1}$ Economic School of Hefei University of Technology, Hefei, Anhui, 230601, PR. China \\ aahzbz@126.com, ${ }^{b} 693502692 @ q q . c o m$ \\ ${ }^{*}$ Corresponding author
}

Keywords: Voluntary Information Disclosure, Stock Price Synchronicity, Accounting Standards.

\begin{abstract}
This paper uses Shanghai and Shenzhen 300 index constituent stocks to analyze the effect of the degree of voluntary information disclosure on Chinese stock price synchronicity from two dimensions: quantity and quality. Meanwhile, this paper discusses how the changes in accounting rules influence the relationship between voluntary information disclosure and stock price synchronicity. The result shows that voluntary information disclosure is negatively related to stock price synchronicity. Moreover, the improvement of accounting standards, on the one hand, is likely to decrease stock price synchronicity; and on the other hand, increases the negative relationship between voluntary information disclosure and stock price synchronicity.
\end{abstract}

\section{Introduction}

Firm-specific information is one of the main factors that lead to changes in stock price of listed companies. Due to information asymmetry in the stock market, investors are unlikely to acquire this information, therefore, the fluctuation of stock price tends to manifest the changes in market macro-information, which in turn, leads to higher synchronicity in stock price and affects the efficiency of resource allocation in capital market. Through the increase in voluntary information disclosure, listed companies can reduce the degree of information asymmetry in the stock market. Therefore, investors can obtain more firm-specific information, make right investment decisions and improve the pricing efficiency in the stock market. China's ministry of finance carried out two reforms in accounting standards in 2007 and 2013 respectively in order to make Chinese accounting rules in line with international standards. It seems that accounting standards can directly influence both quality and quantity of accounting information to be disclosed as accounting rules are the institutional norms of accounting information. Then, how does the voluntary information disclosure affect stock price synchronicity? Whether the improvement in accounting standards affects the relationship between voluntary information disclosure and stock price synchronicity? It'll have significant implications to discuss Chinese listed companies' choices in information disclosure and evaluate the results of the improvement in accounting standards.

\section{Literature Review}

By using CAPM, King(1966)[1] found that stock price included some information from both market level and industry level. Later, Roll(1988)[2] indicated that the more information included in the stock price, the more consistent in the fluctuation of stock price and overall market, and the higher synchronicity of stock price would be. Jin and Myers(2006) [3] found that the difference of stock price depended on information transparency in different market environments. Healy et al'(1999)[4] research showed that as different stocks in the same market were given, the higher degree of information transparency of a company, the more firm-specific information was contained in the stock price, the lower the synchronicity of stock price. When it comes to the question of how firm-specific information is contained in stock price and further affects the synchronicity of stock price, Ferrira(2007) [5] believed that firm-specific information is reflected in stock price by the means of information disclosure. 
Information disclosure is separated into compulsory disclosure and voluntary disclosure. While voluntary information disclosure, as one of the main forms of information disclosure, has played an important role in the stock price. Barberis (2005)[6] thought that as the risk of information asymmetry was increasing in stock market, the quality of voluntary information disclosure was becoming more and more important. Investors choose to invest in the companies only if they can get accurate information of these companies. Zhang (2005)[7] found that the greater the efficiency in decision-making of voluntary information was, the greater demand for investors to hold the stocks, and the higher the stock price would be.

The company's accounting information is major component of voluntary information disclosure, Cheng(2012)[8] indicated that accounting information was seen as one of the most important information sources for investors, the quality of accounting information directly influenced the efficiency of resource allocation in stock market, which in turn, influenced the formation of stock price. Jin's study showed that the improvement of new accounting standards had influenced the relationship between the quality of accounting information and stock price synchronicity.

This paper tries to develop the research from two dimensionalities. One is to construct measurable indicators for voluntary information disclosures from both quality and quantity levels, and to analyze the relationship between voluntary information disclosure and stock price synchronicity. The other is to put new accounting standards and voluntary information disclosure into a new framework and to analyze how the improvement in accounting standards affects the relationship between the degree of voluntary information disclosure and stock price synchronicity.

\section{Theoretical Analysis and Research Hypothesis}

\section{Voluntary Information Disclosure and Stock Price Synchronicity}

Stock price synchronicity means the degree of convergence between company's stock price fluctuation and market price fluctuation, in other words, stock price present "go up and fall together". Fama (1991)[9] put forward "efficient market theory" and hold the view that price reflected all available information in an efficient capital market. This conclusion was conditioned on the hypothesis that investors in the efficient market could identify and select useful information and then made reasonable investment decisions. Therefore, the more firm-specific information was disclosed in the stock market, the more useful information could be used by investors, the more real company value was contained in the stock price, the lower the stock price synchronicity would be.

Recently, compulsory information disclosure creates not much difference among listed companies in China, however, voluntary information disclosure will play a more important role in Chinese stock market as the system of information disclosure for listed companies is continued to be developed. Therefore, listed companies should increase voluntary information disclosure in order to promote openness, transparency and sufficiency of market information through full information disclosure. This will make investors grasp more efficient information and lead the formation of reasonable stock price, strengthen the efficiency of stock market and reduce stock price synchronicity based on investor's own judgments.

In addition, the degree of company's voluntary information disclosure can be investigated from both quality and quantity levels. In terms of quantity level, the more financial reports that listed companies disclosed, the higher the degree of voluntary disclosure. From quality level, the more efficient and relevant of information listed companies disclosed voluntarily, the higher the degree of voluntary disclosure. Based on the above-mentioned analysis, we put forward the following two hypotheses:

$\mathrm{H}_{1 \mathrm{a}}$ : There is a negative relationship between the quality of voluntary information disclosure and stock price synchronicity.

$\mathrm{H}_{1 \mathrm{~b}}$ : There is a negative relationship between the quantity of voluntary information disclosure and stock price synchronicity. 


\section{The Improvements in Accounting Standards and Stock Price Synchronicity}

In 2007, China carried out the first reform in accounting standards and made a huge success, and then in 2013, it adjusted some parts of new accounting standards, such as fair value measurement, employees' salary, etc. Therefore, it symboled all-round improvements for the quality of Chinese accounting standards and the convergence with IFRS. The improvements of accounting standards increase the comparability, transparency, efficiency and intelligibility of accounting information, better reflect company's financial and economic situation, and make investors better understand and grasp company's accounting information. As the contents of firm-specific information are increased in the stock market, the relative ratio between firm-specific information and market level information is promoted and the stock price synchronicity is reduced. Therefore, this paper puts forward the following hypothesis:

$\mathrm{H}_{2}$ : The improvements in accounting standards can reduce stock price synchronicity.

\section{Accounting Standards Improvements, Voluntary Information Disclosure and Stock Price Synchronicity}

From two perspectives, the improvement of accounting standards will strengthen the negative relationship between voluntary information disclosure and stock price synchronicity. On one hand, new accounting rules adjust partial important contents of disclosed information, so that the quality of firm-specific information is promoted as well as the intelligibility and decision-relevance, which reduces stock price synchronicity; on the other hand, the new accounting standards enhance the disclosure requirements for listed companies' compulsory information disclosure. When all listed companies increase the quantity of disclosed information, an incentive effect will be generated. That is, some listed companies will selectively disclose more information in order to optimize their public images, to expand the differential degree from other companies in terms of voluntary information disclosure, and to strength investors' confidence for the company (Chen,2013)[10]. Therefore, investment demands are stimulated and stock price are promoted. This incentive-effect will generate the competitive effect and encourage more and more companies to boost the quantity of voluntary information disclosure. Based on above-mentioned analysis, we propose the following two hypotheses:

$\mathrm{H}_{3 \mathrm{a}}$ : The improvements in accounting standards will strength the negative relationship between the quantity of voluntary information disclosure and stock price synchronicity.

$\mathrm{H}_{3 b}$ : The improvements in accounting standards will strength the negative relationship between the quality of voluntary information disclosure and stock price synchronicity.

\section{Empirical analysis}

\section{Model Construction and Variables Selection}

Model construction. In order to test the hypotheses, we set up equation (1) and (2):

$$
\begin{aligned}
& \text { Syn }_{i, t}=a_{0}+a_{1} \text { Iquantity }_{i, t}+a_{2} \text { Rule }_{i, t}+a_{3} \text { Iquantity }_{i, t} \times \text { Rule }_{i, t}+X_{i, t}+\varepsilon . \\
& \text { Syn }_{i, t}=a_{0}+a_{1} \text { Opaque }_{i, t}+a_{2} \text { Rule }_{i, t}+a_{3} \text { Opaque }_{i, t} \times \text { Rule }_{i, t}+X_{i, t}+\varepsilon .
\end{aligned}
$$

where Syn denotes stock price synchronicity; Iquantity is the quantity of voluntary information disclosure; Opaque is the quality of voluntary information disclosure; Rule is the improvements in accounting standards; $X$ stands for other control variables that influence stock price synchronicity; Iquantity $\times$ Rule and OpaquexRule represent the improvements of accounting standards and the interaction of the quality and quantity of voluntary information disclosure respectively, and these two variables are used to investigate whether the improvements of accounting standards can increase the influence of the degree of voluntary information disclosure on stock price 
synchronicity.

Variable selection. (1) Explained variable: Syn

According to Roll (1988)[2] and Morck (2000)[11], this paper uses CAPM model to separate stock yield into market level yield, industry level yield and company level yield, as equation (3):

$$
r_{i, t}=\beta_{0}+\beta_{1} r_{m, t}+\beta_{2} r_{I, t}+e_{i, t} .
$$

where ri,t is stock yield in week $t$; rm,t is market yield in week $t$; $r I, t$ is industry yield in week $t$; e is residual, means partial yield that can't be explained by market level and industry level. R 2 of equation(3)reflects the ratio of market level information and industry level information to the explanatory parts of yield changes in individual stocks. And the range of R2 is $(0,1)$.

Following Durnev etl. (2003)[12], we define Syn as

$$
\operatorname{Syn}_{i}=\ln \left[R_{i}^{2} /\left(1-R_{i}^{2}\right)\right]
$$

\section{(2)Explanatory variables}

This paper takes the quantity of voluntary information disclosure (Iquantity) and the quality of voluntary information disclosure (Opaque) as proxy variables for the degree of voluntary information disclosure. According to Wang and Jiang(2004)[13], we use the quantity of listed companies' announcements to measure the number of voluntary information disclosure, where the quantity of announcements equal to the total number of temporary announcements and quarter announcements. In addition, we follow Bhattacharya (2003)[14] , use surplus reports to measure the quality of voluntary information disclosure for Chinese listed companies and choose yield opacity to measure the quality of information disclosure 1.

(3) Controlled variables

We select some controlled variables to represent the basic characteristics of listed companies2. The detailed definition of the variables can be seen in Table 1 .

Tab.1 The definition of controlled variables

\begin{tabular}{l|l|c}
\hline Symbol & Definition & Expected \\
\hline Size & The size of the company which equals to the natural logarithm of the & + \\
\hline Sharehr & Measure the concentration of ownership which equals to the ratio of & + \\
\hline ROA & Measure the profitability which equals to the all capital earnings rate. & + \\
\hline NPM & Measure the profitability which equals to net profit margin on sales & + \\
\hline PB & Measure the growth which equals to the company's book value. & - \\
\hline Vol & Measure the liquidity which equals to the average annual volume of & + \\
\hline TR & Measure the liquidity which equals to the average annual turnover of & - \\
\hline
\end{tabular}

\section{Sample selection and data sources}

In the paper, Chinese listed companies in Shanghai and Shenzhen 300 Index constituent stocks are chosen as the samples over the period of 2004 to 2013. By following Jin and Myers' (2006)[3] approach, this paper excludes the financial listed companies and samples with incomplete data. Finally we get 134 companies and receive a total number of 1342 observations. The data in this paper is from the Wind database.

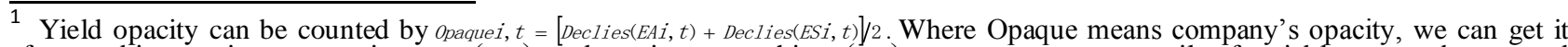
after combine earnings aggressiveness (EA) and earnings smoothing (ES). Declies (.) is ten percentile of variable. EA can be counted by $E A i, t=A C C i, t / T A i, t-1$. Where $\mathrm{TA}_{\mathrm{i}, \mathrm{t}-1}$ is total value of output on t-1year, $\mathrm{ACC}_{\mathrm{i}, \mathrm{t}}$ is steerability accrued items on $\mathrm{t}$ year and can be counted by $A C C i, t=\Delta C A i, t-\triangle C L i, t-\triangle C A S H i, t+\triangle S T D i, t-D E P i, t+\triangle T P i, t$. Where $\triangle C A$ is increased number of liquid assets, $\triangle C L$ is increased number of liquid debt, $\Delta \mathrm{CASH}$ is increased number of monetary capital, $\Delta \mathrm{STD}$ is increased number of annually long-term debt, DEP is distribution expense and depreciation expense, $\triangle T P$ is increased number of tax. ES can be counted by $E S i, t=\operatorname{Correl}(\triangle A C i, t, \triangle C F i, t)$. Where $\triangle \mathrm{AC}$ is increased number of steerability accrued items, $\Delta \mathrm{CF}$ is increased number of cash flow, Correl

2 Jin and Myers (2006) thought that the degree of Syn was connected with the transparency level of economic entities, which can be reflected by the company's fundamental index.
} 


\section{Empirical Results}

This paper uses STATA 12.0 to conduct panel fixed effects regression analysis. Table 2 reports the empirical results. In Model (1), the regression coefficient of Iquantity is significantly negative, which confirms H1a. In Model (2), the regression coefficient of Opaque is significantly positive, which is consistent with H1b. In addition, from the coefficients of Rule in Model (1) and Model (2), we find that the improvement in accounting standards reduces the stock price synchronicity, which confirms H2. In Model (3), the regression coefficient of Iquantity $\times$ Rule is significantly negative, which testifies H3a. In Model (4), the regression coefficient of OpaquexRule is significantly positive, which testifies H3b. For explained variables, the coefficient signs of Size, PB, Vol and TR are consistent with our expectations. But the coefficient of Sharehr is not significant, Li's study shows that there is a U-shaped relationship between the shareholding ratio of the largest shareholder in the company and the stock price synchronicity. However, the relationship between shareholding ratio of other shareholders in the company and the stock price synchronicity is negative. Since this paper choses shareholding ratio of the top ten shareholders to measure the concentration of ownership, it is possible to generate positive and negative results which may cancel each other out, and in the end leads to an insignificant result. The coefficient of ROA is significantly positive or insignificant. According to Healy et.al'(1999)[4] study, ROA that is too high or too low both will deviate from the market average level, resulting in its impacts on the stock price synchronicity in different regression equations are not necessarily the same. The coefficient of NPM is significantly negative or not significant as the change in NPM is determined by the changes in profits and revenue together. When the revenue is increasing, the corresponding sales expenses, financial expenses and management fees, etc. will increase as well. Therefore, it will affect the judgment of investors and generate uncertainty effects on stock price synchronicity.

Tab.2 Results of panel regression

\begin{tabular}{|c|c|c|c|c|}
\hline Variable & Model (1) & Model(2) & Model(3) & Model(4) \\
\hline Iquantity & $\begin{array}{c}-0.0059^{* * *} \\
(-6.11)\end{array}$ & & $\begin{array}{c}-0.0045^{* * *} \\
(-4.13)\end{array}$ & \\
\hline Opaque & & $\begin{array}{c}2.9637^{* * * *} \\
(7.37)\end{array}$ & & $\begin{array}{c}2.3733^{* * *} \\
(4.79)\end{array}$ \\
\hline Rule & $\begin{array}{c}-0.3679^{* * *} \\
(-6.34)\end{array}$ & $\begin{array}{c}-0.6334^{* * *} \\
(-10.01)\end{array}$ & $\begin{array}{c}-0.1580^{*} \\
(-1.65)\end{array}$ & $\begin{array}{c}-0.8160^{* * *} \\
(-7.42)\end{array}$ \\
\hline Iquantity $\times$ Rule & & & $\begin{array}{c}-0.0040^{* * *} \\
(-2.75)\end{array}$ & \\
\hline OpaquexRule & & & & $\begin{array}{c}2.0667^{*} \\
(2.03)\end{array}$ \\
\hline Size & $\begin{array}{c}0.1654^{* * * *} \\
(2.89)\end{array}$ & $\begin{array}{l}0.0097 \\
(0.19)\end{array}$ & $\begin{array}{c}0.1530^{* * *} \\
(2.67)\end{array}$ & $\begin{array}{l}0.0285 \\
(0.54)\end{array}$ \\
\hline Sharehr & $\begin{array}{c}0.4182 \\
(1.27)\end{array}$ & $\begin{array}{l}0.4195 \\
(1.28)\end{array}$ & $\begin{array}{l}0.4406 \\
(1.34)\end{array}$ & $\begin{array}{c}0.4274 \\
(1.30)\end{array}$ \\
\hline ROA & $\begin{array}{c}0.9443^{*} \\
(1.68)\end{array}$ & $\begin{array}{c}0.6801 \\
(1.22)\end{array}$ & $\begin{array}{c}0.9180^{*} \\
(1.65)\end{array}$ & $\begin{array}{c}0.7009 \\
(1.26)\end{array}$ \\
\hline NPM & $\begin{array}{l}-0.1831 \\
(-1.43) \\
\end{array}$ & $\begin{array}{c}-0.2217^{*} \\
(-1.74) \\
\end{array}$ & $\begin{array}{c}-0.1819 \\
(-1.52) \\
\end{array}$ & $\begin{array}{c}-0.2191^{*} \\
(-1.73) \\
\end{array}$ \\
\hline PB & $\begin{array}{c}-2.9100^{* * *} \\
(-3.37)\end{array}$ & $\begin{array}{c}-5.1987^{* * *} \\
(-5.77)\end{array}$ & $\begin{array}{c}-3.5797^{* * *} \\
(-4.00)\end{array}$ & $\begin{array}{c}-5.6038^{* * *} \\
(-6.08)\end{array}$ \\
\hline Vol & $\begin{array}{c}0.3133^{* * *} \\
(6.89)\end{array}$ & $\begin{array}{c}0.2937^{* * *} \\
(6.53) \\
\end{array}$ & $\begin{array}{c}0.3171^{* * * *} \\
(6.99) \\
\end{array}$ & $\begin{array}{c}0.3078^{* * * *} \\
(6.77)\end{array}$ \\
\hline TR & $\begin{array}{c}-15.2214^{* * * *} \\
(-5.74)\end{array}$ & $\begin{array}{c}-11.7949^{* * *} \\
(-4.62)\end{array}$ & $\begin{array}{c}-15.9320^{* * *} \\
(-6.00)\end{array}$ & $\begin{array}{c}-13.7314^{* * * *} \\
(-5.04)\end{array}$ \\
\hline $\mathrm{R}^{2}$ & 0.2744 & 0.2125 & 0.2729 & 0.2160 \\
\hline
\end{tabular}




\section{Conclusions}

This paper takes the Shanghai and Shenzhen 300 Index constituent stocks as samples, investigates the level of voluntary disclosure (two dimensions: quantity and quality) and the effects of accounting standards on stock price synchronicity. It also discusses how the changes in accounting rules affect the relationship between voluntary disclosure and stock price synchronicity. The conclusions are summarized as: First, the higher quality and greater quantity of voluntary disclosure are, the lower stock price synchronicity will be. Second, improved accounting standards increases the flow of company's characteristic information contents into the securities market, which reduces stock price synchronicity. Third, the improvements of accounting standards increase the quantity and quality of voluntary information disclosure, and further enhance the negative relationship between voluntary information disclosure and stock price synchronicity.

This study has the following implications: (1) voluntary information disclosure of Chinese listed companies should be guided from both "quantity" and "quality" of voluntary disclosure. While listed companies are encouraged to disclose more characteristic information to investors, they should also improve the quality of information and enhance the decision-making availability. (2) The setting-agency of accounting standards in China should uphold the principle of improving the intelligibility of accounting information, combine with the reality, and constantly improve accounting standards and the quality of accounting information.

\section{Acknowledgement}

This research is financially supported by the National Social Science Foundation of China (Grant No. 14BJY181).

\section{References}

[1] B. King, Market and industry factors in stork price behavior, J. Journal of Business. 39 (1966) 139-190.

[2] R. Roll, R2, J. Journal of Finance. 43 (1988) 541-566.

[3] L. Jin, S.C. Myers, R2 around the world: new theory and new tests, J. Journal of Financial Economics. 79 (2006) 257-292.

[4] P. Healy, A. Hutton, K. Palepu, Information asymmetry, corporate disclosure, and the capital markets: a review of the empirical disclosure literature, J. Journal of Accounting and Economics. 31 (1999) 405-440.

[5] M.A. Ferrira, P.A. Laux, Coporate, governance, idiosyncratic risk, and information flow, J. Journal of Finance. 62 (2007) 951-989.

[6] N. Barberis, A. Shleifer, J. Wurgler, Comovement, J. Journal of Financial Economics. 75 (2005) 283-317.

[7] Z.X. Zhang, X.R. Zhang, S.G. Liao, Is the Chinese corporate voluntary disclosure efficient, J. China Economic Quarterly. 2 (2005) 369-386.

[8] H.Y. Cheng, The research of voluntary disclosure and mandatory disclosure, J. Communication of Finance and Accounting. 33 (2012) 69-71.

[9] E. Fama, Efficient Capital Markets, J. Journal of Finance. 46 (1991) 1575-1617.

[10] P. Chen, Information disclosure quality, investor confidence and corporate value, J. Communication of Finance and Accounting. 12 (2013) 53-56. 
[11] R. Morck, B. Yeung, W. Yu, The information content of stock markets: Why do emerging markets have synchronous stock price movements, J. Journal of Financial Economics. 58 (2000) 215-260.

[12] A. Durnev, R. Morck, A. Sweeney, Detecting earnings management, J. The Accounting Review. 70 (2003) 2-42.

[13] W. Wang, G.F. Jiang, Information disclosure, transparency and the cost of capital, J. Economic Research Journal. 7 (2004) 107-113.

[14] U. Bhattaeharya, H. Daouka, M. Welker, The world price of earning of opacity, J. The Accounting Review. 78 (2003) 641-678. 